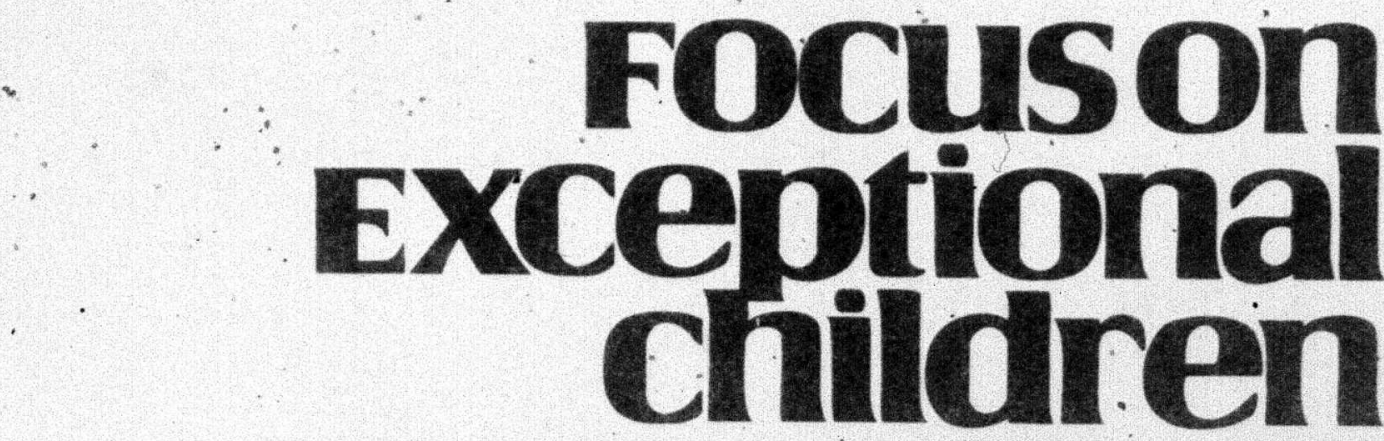

\title{
Behavioral Profiles of Children At-Risk for Emotional and Behavioral Disorders: Implications for Assessment and Classification
}

\author{
Kathleen M. Lambros, Sharon L. Ward, Kathleen M. Bocian, \\ Donald L. MacMillan and Frank M. Gresham
}

Assessment and classification of school-aged children with emotional and behavioral disorders (EBD) have proven to be difficult for school personnel and educators alike (Gresham, 1985; Smith, Wood, \& Grimes, 1988). Current epidemiological research indicates that at least $7 \%$ of children under age 18 may have emotional disorders, yet fewer than $1 \%$ of school-aged children are served as seriously emotionally disturbed (SED) (U. S. Department of Education, 1991). In California, prevalence rates of SED are even lower than the national rate, illustrating the extent of underidentification. Quite often students are not identified as emotionally/behaviorally disturbed (EBD), until the concluding elementary years. This has grave implications for the efficacy of intervention (Walker, Colvin, \& Ramsey, 1995). More typically, students who exhibit externalizing problem behaviors are classified and placed under the learning disability (LD) category (Duncan, Forness, \& Hartsough, 1995, Gresham, 1985, MacMillan, Gresham, \& Bocian, in press).

School or Student Study Teams seem to underidentify and have difficulty in assessing SED for a variety of reasons including:

- the ambiguity of the state definitions

- school psychologists' lack of training in conducting SED assessments

- financial limitations of school districts, and

- hesitation to use labels such as BD/EBD/SED.

Despite evidence to the contrary (JacMillan. Jones, \& Aloia, 1974), the pervasive notion that the act of labeling exacerbates the condition influences individual decisions in classification, and school personnel choose to use a more socially desirable label such as LD (Gresham, 1985). Therefore, despite meeting several eligibility criteria, it seems that EBD students are not classified correctly, which lessens their chance to receive the treatment that best serves their needs.

The current definition of SED (Federal Register, 42, 474, 1977) as proposed under provisions of the Individuals with Disabilities Education Act (IDEA), lists five areas or behavioral characteristics that define SED, as follows:

A condition exhibiting one or more of the following characteristics over a long period of time and to a marked degree which adversely affects school performance:

The authors are affiliated with the University of California, Riverside. 
(a) An inability to learn which cannot be explained by intellectual, sensory, or health factors.

(b) An inability to build or maintain satisfactory relationships with peers and teachers.

(c) Inappropriate types of behavior under normal circumstances.

(d)General pervasive mood of unhappiness or depression.

(e) A tendency to develop physical symptoms or fears associated with personal/school problems.

The current definition of SED excludes children who are socially maladjusted, yet it provides no direction or specific criteria that should be used to exclude. Further confusion and lack of precision result when schools equate conduct disorder, externalizing behaviors, and juvenile delinquency with the social maladjustment clause, as this successfully excludes many of the children who otherwise might be identified correctly (Slenkovich, 1992). In addition, identifying a child as SED precludes the possibility of expulsion for the very behaviors that are problematic for the school.

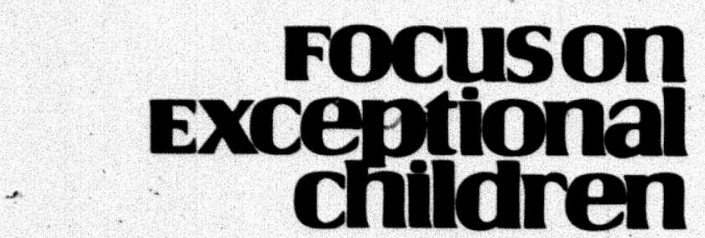

ISSN 0015-5IIX

FOCUS ON EXCEPTIONAL CHILDREN (USPS 203-360) is published monthly except June. July, and August as a service to teachers. special educators, curriculum specialists, administrators, and those concerned with the special education of exceptional children. This publication is annotated and indexed by the ERIC Clearinghouse on Handicapped and Gifted Children for publication in the monthly Curren Index to Joumals in Education (CUE) and the quarterly index. Exceptional Children Education Resources (ECER). The full text of Focus on Exceptional Children is also available in the electronic versions of the Education Index. It is also available in microfilm from Xerox University Microfilms, Ann Arbor, MI. Subscription rates: Individual, \$30 per year: institutions, $\$ 40$ per year, Copyright $\odot$ 1998, Love Publishing Company. All rights reserved. Reproduction in whole or part without written permission is prohibited. Printed in the United States of America. Periodicals postage is paid at Denver, Colorado. POSTMASTER: Send address changes to:

$$
\begin{gathered}
\text { Love Publishing Company } \\
\text { Executive and Editorial Office } \\
\text { P.O. Box } 22353 \\
\text { Denver, Colorado } 80222 \\
\text { Telepnone (303) } 757.2579
\end{gathered}
$$

University of Kansas

Richard J. Whelan

University of Kansas Medical Center
Edward L. Meyen

Thomas Love

Stanley F. Love

Publisher

Associate Editor
Glenn A. Vergason Georgia State University
The behavioral correlates associated with emotional and behavioral disorders include maladaptive patterns of responding that are commonly designated as externalizing or internalizing in nature. Externalizing or undercontrolled behavior problems are characterized by a host of defiant, aggressive, disruptive, and noncompliant responses. Conduct disorder, oppositional defiant disorder, and attention deficit disorder are but a few examples of externalizing behavior. Externalizing behavior problems in children and adolescents represent a widespread and troublesome obstacle for parents, teachers, schools, society, and the individual child who engages in it (Walker et al., 1995, Webster-Stratton, 1993). These behaviors typically are seen in all children at one time or another. For the emotionally or behaviorally disordered child, however, these same behaviors often escalate and magnify into patterns that persist throughout a child's life. Ultimately, this response pattern evolves into psychiatric problems, social maladjustment, and criminal acts (Kazdin, 1987).

In the context of the classroom, externalizing behaviors seem to be more intolerable to teachers than other undesirable behaviors because they directly challenge the teacher's authority, interfere with the delivery of instruction, disrupt classroom routines, and affect classmates adversely (McConaughy \& Skiba, 1993; Safran \& Safran, 1987). Relentless disruptive and noncompliant behavior requires training for effective management, and, according to Kaufman and Wong (1991), many general education teachers do not have sufficient behavior management training to control such aversive behavior. Thus, teacher tolerance for externalizing-type behavior is low and, in turn, referral for externalizing behavior far exceeds that of internalizing-type referrals (Walker \& Fabre, 1987).

Internalizing behavior patterns can include, but are not limited to, withdrawal, shyness, depression, dysthymia, emotional and personality disorders. In general, internalizing or overcontrolled behaviors are more inner-directed and covert in nature. These behavior patterns also are predictive of social adjustment difficulties and psychopathology in later life (Achenbach, 1985). Because of their internal or private nature, however, they do not readily come to the attention of teachers or authorities. Quite often such behaviors are not seen as difficulties and, therefore, are overlooked in assessment and not subject to direct interventions within the school systems.

In recent literature the comorbidity of externalizing and internalizing behavior patterns has been suǵgested by Loney (1987) and by McConaughy \& Skiba, (1993). Often, conductdisordered and antisocial youth also present with low self-esteem, low self-concept, and depression (Walker et äl., 1995). Characteristic behaviors that comorbid children exhibit are highly correlated with hyperactivity (ADHD), explosiveness, 
impulsivity, academic failure, and poor social skills (Campbell, Gonzalez, \& Silva, 1992). This comorbid diagnosis, which seriously hinders the development and functioning of many children, is increasingly prevalent (Loney, 1987, McConaughy \& . Skiba, 1993). These students are at higher risk for high school dropout, gang affiliation, juvenile offenses, substance abuse, and teen pregnancy (Walker et al., 1995). Their complex problems warrant more intensive intervention efforts.

Although SED children currently are underidentified and frequently are not served as such until the later educational years, the evidence indicates that intervention efforts are more likely to enjoy success when applied during earlier ages. According to Walker et al. (1995), maladaptive behavior patterns that remain untreated by the third grade should be considered a chronic disorder that has no cure and at best can be managed given appropriate strategies. Early identification, prevention, and screening procedures may well aid in eliminating behavior patterns before they can progress into conduct disorder, depression, and the like. A more preventive, rather than reactive, approach is necessary (Walker et al., 1995).

Valid and reliable assessment of SED necessitates multimethod assessment practices and early identification. Duncan et al. (1995) reported a considerable lag time between initial SED symptoms/behavior and referral for services, classification/diagnosis, intervention efforts, and educational placement. In addition, discrepancies are present between clinical diagnosis (e.g., employing DSM-IV) and school classification (IDEA) systems, which pose further obstacles for prevention and early identification of SED. The need for appropriate placement, is crucial, wherein the student can receive intensive intervention to remediate and redirect challenging behaviors. Research has indicated that a process of least to most restrictive placements (i.e., regular $\mathrm{Ed} \rightarrow \mathrm{RSP} \rightarrow \mathrm{SDC}$ ) is most often adopted (Duncan et al., 1995). The underlying premise of LRE was to mandate appropriate placement, not sequential movement on a continuum from regular education to special day classes. While current trends in litigation are supporting education within the regular education classroom (full inclusion), this practice may not always serve the best interest of the child with emotional and behavioral disorders (MacMillan, Gresham, \& Forness, 1996).

The use of empirically-based assessment methods is paramount in the identification and classification of students with EBD. Empirically based assessments are procedures based upon direct observations and experience (Achenbach, 1985) which have several benefits over clinical methods for assessing children's emotional and behavioral functioning (Edelbrock, 1983). These advantages include: (a) quantitative scores from rating scales which provide more reliable measures of functioning than do subjective judgments, (b) com- parison to normative samples which corroborate and enhance judgments of deviance in reported behavior, ( c) multiple items, which can be incorporated to represent a diverse range of problems, and (d) minimal time and training to administer, which make rating scales an efficient and economical method of assessment. Empirically based multi-informant assessment provide a more comprehensive basis for making these categorical decisions such as special education eligibility.

Walker and Severson (1990) developed a multiple gating procedure, the Systematic Screening for Behavior Disorders (SSBD), which employs a progression of screening and assessment stages, beginning with general screening tools, and advancing to more precise and stringent evaluations. Stage 1 requires the teachers to rank order their students on externalizing and internalizing behavior patterns.

In Stage 2 the teacher completes a behavior checklist, the Critical Events Index (CEI). This tool is a 33 -item teacher checklist of behavioral events having high intensity and salience but relatively low frequency (e.g., fire-setting, physical assault of another, self-abuse). Past research has demonstrated that the CEI separates the more severe cases of EBD even within a restricted sample of youth in residential care (Duncăn, Forness, \& Hartsough, 1995). In school settings the CEI identified students had lower social skills and higher externalizing problem behaviors within a sample of at-risk children (Gresham, MacMillan \& Bocian, 1996). Further examination of the CEI as a screening component in the assessment of EBD is warranted.

In the present article we attempt to identify the earliest, most efficient, and accurate predictors of EBD. To examine the correlates of EBD, a group of third-grade students was classified as being at high-risk for emotional and behavioral disorders, based on a criterion-level CEI score. These "high risk" (HR) students were drawn from a larger sample of third graders that included students at risk for academic failure (AR) and students achieving at grade level, the control group (CC).

Mean differences were examined between these three groups on a host of variables including teacher ratings of academic competence and interpersonal social skills, student selfconcept ratings, and peer sociometric status ratings. In addition, these dependent variables were- considered for their utility as significant predictors of group membership, or their ability to classify children effectively into HR, AR, or CC groups. These data also will illustrate that, although the HR or EBD groups evidence nearly all of the eligibility criteria of the current SED definition, they are not being served as such under IDEA. Finally, our efforts to characterize children at risk for EBD (HR) as a homogeneous group, will be tempered by an examination of the behavior profiles of three HR students. These profiles illustrate the variability of comorbidity-morbidity and intervention needs of students who meet the SED criteria. 


\section{METHODS}

\section{Participants And Procedures: Initial Sample}

The original sample consisted of $\mathbf{4 3 6}$ third-grade children, drawn from 24 elementary schools in five southern California school districts, who were part of a longitudinal study supported by the U. S. Department of Special Education. Students were selected for the study using the following procedures:

1. "At-risk" students were identified by their third-grade teachers during the fall of the 1993-94 (Cohort 1) or 1994-95 (Cohort 2) academic year.

2. Informed parental consent was solicited immediately for each of the cohorts. Sample demographics were computed for the at-risk sample.

3. Within each cohort control students were selected to match the demographics of the at-risk sample and informed parental consent solicited for children selected as control subjects. The ratio of at-risk to control students was approximately 3 to 1 .

At-risk students were defined as children who had been, or were being considered for, referral to the Student Study Team (SST) for academic or behavioral problems. In California the SST is a multidisciplinary team composed of school faculty and staff members who work with the classroom teacher to design interventions for children at risk for academic failure or behavior problems as a general education intervention preceding formal evaluation for special education eligibility. If these interventions are deemed unsuccessful after a trial period, the SST may recommend formal psychological assessment for the child to determine cognitive aptitude, processing disorders, and so on that may qualify the child as eligible for special education services. Control students were children in the same grade level or class as the at-risk sample who were achieving at grade level, did not exhibit behavior problems, and had not been referred to SST.

For both cohorts we were able tơ achieve reasonable matches in demographics between the at-risk and control portions of the sample. The final sample consisted of $64.3 \%$ males and $36.7 \%$ females, with an ethnic breakdown of $38 \%$ Caucasian, 25.5\% Black, and 35.5\% Hispanic students.

We did not anticipate differences between the cohorts, as Cohort 2 was drawn from many of the same sthools as Cohort 1 , and the use of two cohorts stemmed from logistics of sample selection and sufficient time to assess each of the children in the study adequately, rather than study design or differences in treatment. Mean differences and percentages within categorical data were examined between the cohorts, and no significant differences were noted. For the purpose of this article, the data were collapsed across cohorts. Refer- ences to time periods will be made by grade level of the students when the data were collected.

\section{Data Collection: Initial Sample}

Following the sample selection process, initial meetings were held with the students' teachers to distribute a packet of instruments for each student (see the discussion under Instruments) and to schedule dates for administration of individual student tests. Teachers were compensated for their completion of student rating scales, which were collected at the time the individual test was administered. Barring absenteeism and students who moved from th initial school location, project staff attempted to complete all data collection for each point in time over the course of the study within a 2 -month period.

\section{At-Risk For EBD Sample Selection: High Risk, Low Risk And Control Students}

The sample of students under discussion here was drawn from the original sample described above. Participants were 155 children in third grade with a mean chronological age of 8.92 and a standard deviation of .66 . Among the students, $84.6 \%(n=131)$ were males and $15.4 \%(n=24)$ were females. An ethnic breakdown of this smaller, selected sample revealed that $56.8 \%$ were Caucasian $(n=88), 20.0 \%$ were Black, $(n=31), 21.3 \%$ were Hispanic $(n=33)$ students, and $1.9 \%$ were Asian $(n=3)$. In much the same manner as employed with the original sample of 436 students, selection of the 155 students was determined by first identifying students meeting a highrisk status criterion for EBD, and then creating a demographically matched group of low-risk and control students. The EBD sample composition is notable for the high ratio of males to females ( 5 to 1 ) and the higher percentage of Caucasian students $(57 \%)$ than was true for original sample $(n=436)$.

\section{Definition Of Groups}

Students were classified into one of three groups based on the Critical Events Index (CEI), a behavior checklist completed by the classroom teacher. The CEI is one component of the Systematic Screening' for Behavioral Disorders (SSBD) (Walker \& Severson, 1990) and indicates less frequent, yet highly salient problem behaviors. The behaviors have been referred to as "behavioral earthquakes," possibly having huge moral, legal, and economical impact. Walker and Severson (1990) report that evidence of even one of these critical behaviors generates reason for concern, and the behavior often will result in referral for further evaluation. Scores ồ the CEI, ranging from 0 to 33 , reflect the total number of eritical events the student exhibited within the past 6 months. 
The CEI has nationally representative norms, based on 4,500 cases, and provides cutoff scores for identifying students as at-risk for behavior disorders. The CEI also has been shown to identify children at-risk for learning disorders, as - well as to differentiate children exhibiting externalizing and internalizing behavior problems from control children (Gresham et al., 1996). The reported stability estimate for a 1month interval is $\underline{\underline{1}} \#=.81$.

Students were considered at high risk for emotional and behavioral disorders if they received a total score of 5 or more on the CEI from their third-grade classroom. CEI data were collected twice during the third-grade year, once in late fall/early winter (third grade: $\mathrm{T} 1$ ) and again in the late spring (third grade: T2), and the criterion score (of 5 or more) could be met at either time period. A total of 51 students met this criterion and formed the HR group.

Low-risk (LR) students were those who were part of the at-risk status of the original sample and had received a CEI score, during both time periods, that was less than 5 and greater than 0 . The control students $(\mathrm{CC})$ were part of the initial sample of control students and had received a CEI score of 0 . The LR and CC students then were stratified by ethnicity and gender and were selected randomly to match the demographic composition of the HR group, with 52 LR students and $52 \mathrm{CC}$ students.

Table 1 provides the means and standard deviations by groups on the CEI. Although the CEI was utilized as the classification variable, the respective group means indicate that the groups are not comparable on the number of salient behaviors they exhibit. On average, the HR group demonstrated three to five more critical behaviors than did the LR group, and four to seven more than the $\mathrm{CC}$ group.

Beyond the frequency or number of critical events recorded on the CEI, the types of behaviors can range from mild to more serious in nature (for example, "is sad" versus "wants to hurt him/herself"). Table 2 displays the most frequent externalizing and internalizing behaviors noted by. teachers for the HR group. Visual inspection of these behaviors indicates that most of these events are cause for clinical concern and indicative of behaviors that are qualitatively different from those of the average misbehaving third grader.

Given this, the data presented in Table 3 are surprising: $73 \%$ of the students in the HR group are served by their thirdgrade teachers in the mainstream classroom without benefit of more intensive and specialized professional assistance. The assumption underlying this finding is that the classroom teachers and the mainstream classroom environments are equipped to intervene with students presenting these levels of problems. As our longitudinal data demonstrate, these placements may not be appropriate for either teachers or students.
TABLE 1

Means and Standard Deviations by
Risk Status Groups on the CEI

\begin{tabular}{|c|c|c|}
\hline \multirow[b]{2}{*}{ Groups } & \multicolumn{2}{|c|}{ Year of Observation } \\
\hline & Grade 3 & Grade 4 \\
\hline \multicolumn{3}{|l|}{ Controls } \\
\hline M & .67 & .25 \\
\hline SD & 1.32 & .77 \\
\hline \multicolumn{3}{|l|}{ At-Risk } \\
\hline M & 1.91 & .78 \\
\hline$S D$ & 2.11 & 1.30 \\
\hline \multicolumn{3}{|l|}{ EBD } \\
\hline$M$ & 4.42 & 6.33 \\
\hline SD & 3.35 & 3.40 \\
\hline
\end{tabular}

TABLE 2

Most Common Items on the CEI

\section{Externalizing Items}

1. Ignores teacher warnings or reprimands

2. Is physically aggressive with other students or adults

$61 \%$

3. Has tantrums

4. Uses obscene language or swears

5. Damages others' property

6. Steals

$55 \%$

$43 \%$

$36 \%$

$31 \%$

$22 \%$

Internalizing Items

1. Exhibits sad affect, depression, and fellings of worthlessness

$43 \%$

2. Demonstrates obsessive-compulsive behaviors $33 \%$

3. Exhibits thought disorders or gets lost in own thoughts

$32 \%$

4. Suddenly cries or displays inappropriate affect in normal situations

5. Complains of severe headaches or other somatic complaints

6. Exhibits painful shyness

$18 \%$

$11 \%$

\section{Data Collection}

Data collected were from multi-source, multi-methods of assessment, including teacher surveys, student-completed surveys and peer sociometric ratings and nominations. As mentioned previously, data were collected twice during the student's third-grade year, once in the late fall/early winter (Fall, Grade 3) and again in the spring (Spring, Grade 3). During the fourth-grade year, data were collected in the early winter (Winter Grade 4). Instruments and surveys were ad- 
TABLE 3

Educational Placement, Fall Grade 3, by Risk Status Group

\begin{tabular}{cccc} 
& \multicolumn{3}{c}{ Educational Placement } \\
$\begin{array}{c}\text { Risk } \\
\text { Status }\end{array}$ & $\begin{array}{c}\text { General } \\
\text { Education }\end{array}$ & $\begin{array}{c}\text { Resource } \\
\text { Specialist }\end{array}$ & $\begin{array}{c}\text { Special } \\
\text { Day Class }\end{array}$ \\
High Risk $(\mathrm{N}=51)$ & 38 & 6 & 8 \\
& $73 \%$ & $12 \%$ & $15 \%$ \\
Low Risk $(\mathrm{N}=52)$ & 42 & 9 & 1 \\
& $80 \%$ & $18 \%$ & $2 \%$
\end{tabular}

ministered to students by graduate students trained in school psychology or education. The following descriptions of the individual instruments are grouped by information source.

\section{Instruments}

\section{Teacher measures}

Social Skills Rating System - Teacher (SSRS-T). The SSRS-T (Gresham \& Elliott, 1990) is a teacher rating of social competence in children. The SSRS teacher form requires the student's classroom teacher to rate the child in three areas of performance:

\section{Social Skills ( 30 items)}

2. Problem Behaviors ( 18 items)

3. Academic Competence ( 9 items)

The Social Skills scale is broken down further into three subscales: Cooperation, Assertion, and Self-Control. The Problem Behavior scale contains behaviors that interfere with more appropriate social skills. This scale contains three subscales: Externalizing, Internalizing, and Hyperactivity. The Academic Competence scale provides a teacher's judgment of the students' academic and/or learning behaviors as compared to the other children in the same classroom. This assessment tool was nationally standardized on a representative sample of 4,170 children. Overall reliability on this measure is high, with a median coefficient alpha reliability of .84 for Problem Behaviors, .90 for Social Skills, and .95 for Academic Competence.

\section{Student measures}

1

Student Self-Concept Scale - Student (SSCS). Students provided self-report data on the SSCS (Gresham, Elliott, \& Evans-Fernandez, 1993), a 72 -item multidimensional scale measuring self-concept in children and adolescents grades 3 12. Items are rated on a 3-point scale of Confidence ranging from "Confident" to "Not At All Sure." Similar ratings of perceived Importance of each behavior also are obtained and range from "Not Important" to "Critical." The SSCS includes three measured domains:

1. Self-Concept of Social Skills, which measures students' self-perceptions in social situations.

2. Self-Concept of Academic Competence, which determines how students feel about their academic and school related abilities.

3. Self-Image, which assesses students' general self-concept and global perception of who they are.

The SSCS was standardized on a nationally representative sample of 3,586 elementary- and secondary-aged students. Test-retest reliability is reported as .73 for elementary students.

\section{Peer measures}

Peer Nominations and Ratings. Peer nomination and peer ratings were modeled after the two-dimensional approach described by Coie, Dodge, and Coppotelli (1982).

Peer Ratings. Within intact classrooms all students, not just the subjects of the research study, were requested to rate each other according to how much they liked to work and play with each other. Names of the participating students were listed on a sheet distributed to the class, and for each person, students marked one of the following choices: "Like to WORK With," "Kind of like to WORK With," or "Do Not Like to WORK With." Similar ratings were collected for play interactions: "Like to PLAY With," "Kind of Like to PLAY With," or "Do Not Like to PLAY With."

Peer Nominations. The nomination portion of the survey requires the peers in each class to nominate three students they "Like the Most" and three they "Like the Least." These nominations were utilized to indicate mutual nominations, or friendship indices, for the students. The total nominations from each domain were summed to yield a Liked Most (LM) score and a Liked Least (LL) score, respectively. The scores then were used to calculate the Social Preference (SP) dimension, how much children in general prefer to be with this child, by subtracting the Liked Least score from the Liked Most score. The Social Impact dimension-how noticeable this child is within the clasşroom-is determined by adding the Liked Most and Liked Least scores.

All of the above scores are standardized within classrooms (they are converted to $\mathrm{z}$ scores having a mean of 0 and a standard deviation of 1). These standard scores are utilized to classify children into the following status groups: Popular (well liked); Neglected (low social impact, neither actively liked or disliked); Controversial (liked by some, actiyely disliked by others); Rejected (actively noticed and disliked within the class), and Average. 


\section{RESULTS}

\section{Statistical Analysis}

Analyses consisted of a series of two-way fixed effects multivariate analyses of variance (MANOVA) using the general linear model. Group membership with three levels (HR, LR and CC) was treated as the fixed-effects factor, and Time (Fall Grade 3; Spring Grade 3; Winter Grade 4) as the random effects factor in all MANOVAs. All multivariate hypotheses were tested and interpreted using Wilks' lambda $(\lambda)$, although all three criteria (Wilks' lambda, Pillai's Trace, and Roy's Maximum Root) led to identical decisions regarding statistical signiticance of effects.

Following all significant multivariate effects, Tukey's HSD was the multiple comparison procedure utilized, and an alpha $(\alpha)$ level of .05 was applied. The Tukey HSD controls for experimentwise Type I error rate and is an appropriate technique when the various groups have unequal numbers of subjects. In the reporting of results, the tests for significant differences will be referred to when discussing the means for each group; however, we will not report all the information details within the MANOVA table here.

\section{Controlling For Missing Data}

Prior to conducting the analyses, the data were examined for missing observations from any one or all of the information sources at any of the three points of data collection. Because of the high mobility of at-risk populations in schools, we anticipated attrition from year to year within the study. Missing data as a result of student attrition (moving from the original school) were ameliorated by flagging and tracking school records of study subjects, visiting the student at the new school and collecting data there, or collecting data longdistance with the classroom teacher's assistance. Although this technique compensated for a portion $(50 \%)$ of attrition, individual sources of missing data could stem from lack of teacher cooperation, excessive student absenteeism, or failure of schools or parents to request student school records

To determine if the students for whom data were missing or who had left the study were different from those who remained for the duration of the study, a series of two-way repeated measures MANOVAs were computed. The first effect was the grouping of students according to Missing versus Non-Missing data during Winter Grade 4 . The second effect was the risk status for EBD (HR, LR, or CC). The dependent measures were the scores on teacher reports, student surveys, or peer sociometric ratings for Fall Grade 3 and in separate analyses, Spring Grade 3.

No significant interaction was found between missing data status in fourth grade and risk status for EBD on teacher measures, self-concept measureš, or peer-rating measures for either time period. Subsequent to this finding regarding the random distribution of missing data across the three groups, all statistical analyses were executed in two ways:

A. Dropping from the analysis those subjects with missing data at any point in time or from any one of the three information sources

B. Retaining subjects who were missing one of the data points, and substituting the individual mean score from the most recent individual scores of the child for the missing data.

As was anticipated, given that there were no significant interactions based on data status in the initial analyses, the significance of main effects or interactions did not alter between procedure A and B. The strategy of substituting a calculated value for missing data (Procedure B) is among the more conservative approaches appropriate when the randomness of the missing data can be verified and when the amount of missing data is too large to drop cases (Dodge, 1985; Tabachnik \& Fidell, 1989). Results of the analyses and the group means produced using procedure $\mathrm{B}$ will be reported here:

\section{Teacher Variables}

A $3 \times 3$ (Group by Time) repeated measures MANOVA using SSRS-T scores showed a large group main effect, $\mathrm{F}$ $(6,258)=22.53, \underline{p}<.0001$, which accounted for $57 \%$ of the between group variance $(\underline{\lambda}=.43)$. Post-hoc analyses showed that all scales, Social Skills, Problem Behavior, and Academic Competence, demonstrated significant univariate effects at each of the three points in time, with the most problematic scores (high problem behaviors, low social skills, and academics) corresponding to risk status. Tukey contrasts revealed that, while the $L R$ and the HR groups had significantly lower scores in Academic Competence than the CC group did, they did not differ from each other until Winter Grade 4. No significant effect resulted for Time or for Group $\mathrm{x}$ Time interaction. The means and standard deviations for the three subscales over three time periods are reported in Table 4.

A. $3 \times 3$ repeated measures MANOVA using the subscales of the SSRS-T Problem Behavior scale also showed a significant group effect, $\underline{\mathrm{F}}(6,240)=21.68, \mathrm{p}=<.0001$, which accounted for $58 \%$ of the between group variance $(\lambda=.42)$. Post-hoc analysis indicated between-group differences in each of the three subscales of Externalizing, Internalizing, and Hyperactive Behavior, with the HR group demonstrating higher scores across all domains. Time effect showed no significant differences, although Group $\mathrm{x}$ Time effect, $\mathrm{F}$ $(12.234)=2.29, \mathrm{p}<.009,(\underline{\lambda}=.80)$, was significant. Post-hoc Tukey contrasts revealed that all three groups differed from each other in every domain, with the exception of the Hyper- 
TABLE 4

SSRS-T Teacher Report by Group

Risk Status Groups
SSRS-T
Academic Competence
Fall Grade 3 T 1
Spring Grade 3
Winter Grade 4
Problem Behavior
Fall Grade 3
Spring Grade 3
Winter Grade 4
Social Skills
Fall Grade 3
Spring Grade 3
Winter Grade 4

\begin{tabular}{|c|c|}
\hline & High risk \\
\hline Mean & Standaro \\
\hline $83.4^{a}$ & \\
\hline $82.5^{a}$ & \\
\hline $81.3^{a}$ & \\
\hline $121.1^{\mathrm{a}}$ & \\
\hline $120.1^{a}$ & 12 \\
\hline $120.1^{a}$ & \\
\hline $81.8^{a}$ & \\
\hline $81.0^{a}$ & \\
\hline $81.1^{a}$ & \\
\hline
\end{tabular}

\author{
Low Risk \\ Mean Standard Deviation
}

$\begin{array}{ll}84.2^{\mathrm{a}} & 10.03 \\ 86.4^{\mathrm{a}} & 10.9 \\ 87.7^{\mathrm{b}} & 11.9\end{array}$

$107.9^{\mathrm{b}} \quad 17.9$

$108.2^{\mathrm{b}} \quad 18.0$

$105.0^{\circ} \quad 18.5$

$88.3^{\mathrm{b}} \quad 11.3$.

$89.0^{\mathrm{b}} \quad 11.2$

$92.0^{\circ}-12.8$
Mean $\begin{aligned} & \text { Control } \\ & \text { Standard Deviation }\end{aligned}$

$102.3^{b}$

$103.4^{b}$

$103.5^{\mathrm{c}}$

12.7

8.9

10.3

13.0

14.2

13.7

$94.2^{c}$

13.7

$107.8^{\mathrm{c}}$

$105.2^{\mathrm{c}}$

$107.3^{\varepsilon}$

Means with the same superscript are not significantly different from each other.

TABLE 5

SSRS-T Problem Behavior Subscale: Esternalizing, Internalizing, and Hyperactive Behavior by Group

Risk Status Groups SSRS-T Problem Behavior

Externalizing

$\begin{array}{ccc}\text { Fall Grade 3 T 1 } & 6.7^{\mathrm{a}} & 3.8 \\ \text { Spring Grade 3 } & 6.3^{\mathrm{a}} & 3.2 \\ \text { Winter Grade 4 } & 6.8^{\mathrm{a}} & 3.1 \\ \text { Internalizing } & & \\ \text { Fall Grade 3 } & 6.0^{\mathrm{a}} & 3.2 \\ \text { Spring Grade 3 } & 6.2^{\mathrm{a}} & 2.8 \\ \text { Winter Grade 4 } & 6.7^{\mathrm{a}} & 2.7 \\ \text { Hyperactive } & & \\ \text { Fall Grade 3 } & 8.2^{\mathrm{a}} & 3.2 \\ \text { Spring Grade 3 } & 7.0^{\mathrm{a}} & 2.6 \\ \text { Winter Grade 4 } & 7.7^{\mathrm{a}} & 2.5\end{array}$

High risk

Mean Standard Deviation

3.8

3.2

3.1

3.2

2.8

2.7

3.2

2.6

2.5

\author{
Low Risk \\ Mean Standard Deviation
}

Control

Mean Standard Deviation

Means with the same superscript are not significantly different from each other.

$\begin{array}{llll}3.5^{\mathrm{b}} & 3.1 & 2.2^{\mathrm{c}} & 2.8 \\ 4.0^{\mathrm{b}} & 2.8 & 2.5^{\mathrm{c}} & 2.9 \\ 3.1^{\mathrm{b}} & 3.0 & 1.5^{\mathrm{c}} & 2.0 \\ & & & \\ 4.4^{\mathrm{b}} & 2.7 & 1.7^{\mathrm{c}} & 1.9 \\ 4.6^{\mathrm{b}} & 2.5 & 1.9^{\mathrm{c}} & 2.0 \\ 4.0^{\mathrm{b}} & 2.4 & 1.7^{\mathrm{c}} & 1.9 \\ & & & \\ 6.2^{\mathrm{b}} & 3.5 & 3.4^{\mathrm{c}} & 3.5 \\ 6.4^{\mathrm{a}} & 2.8 & 3.5^{\mathrm{c}} & 3.6 \\ 5.4^{\mathrm{b}} & 2.8 & 2.7^{\mathrm{b}} & 3.0\end{array}$

activity scale in the Spring of Grade 3, where HR and LR groups were similar. The means and standard deviations for each group are included in Table 5.

\section{Peer Ratings And Nominations}

A $3 \times 3$ (Group $\times$ Time) repeated measures MANOVA using the Play With and Work With z scores showed a moderate' effect for group $\mathrm{E}(12,170)=2.63 \mathrm{p}<.003$, accounting for $29 \%$ of the between-group variance $(\lambda=.71)$. Post-hoc analyses revealed that both Work With and Play With ratings were significant at each of the three points in time, with risk status group corresponding to the lower rating scores. The main effect for Time also was significant, $\mathrm{E}(5,86)=2.97, \mathrm{p} .<.01$, which accounted for $15 \%$ of the variance over time $(\lambda=.85)$. Post-hoc Tukey analyses demonstrated that the $C C$ group had significantly higher peer ratings than did the HR for both Play With and Work With at all points in time; however, by Winter for 


\begin{tabular}{|c|c|c|c|c|c|c|}
\hline $\begin{array}{l}\text { Risk Status Groups } \\
\text { SSRS-T Problem Behavior }\end{array}$ & Mean & $\begin{array}{l}\text { Control } \\
\text { Standard Deviation }\end{array}$ & Mean. & $\begin{array}{l}\mathrm{k} \\
\mathrm{d} \text { Deviation }\end{array}$ & \multicolumn{2}{|c|}{ High Risk } \\
\hline Work With Z Score & & & & & & \\
\hline Fall Grade 3 T 1 & $.17^{\mathrm{a}}$ & .96 & $-.57^{a b}$ & 1.17 . & $-.75^{b}$ & 1.01 \\
\hline Spring Grade 3 & $.44^{a}$ & 1.05 & $-.42^{b}$ & 1.16 & $-.72^{b}$ & 1.13 \\
\hline $\begin{array}{r}\text { Winter Grade } 4 \\
\text { Play With Z Score }\end{array}$ & $.11^{\mathrm{a}}$ & .90 & $-.34^{a}$ & 1.04 & $-1.15^{b}$ & .93 \\
\hline Fall Grade 3 & $.18^{\mathrm{a}}$ & .95 & $-.41^{a b}$ & 1.13 & $-.68^{b}$ & 1.08 \\
\hline Spring Grade 3 & $.40^{\mathrm{a}}$ & 1.04 & $-.33^{b}$ & 1.12 & $-.73^{b}$ & 1.13 \\
\hline Winter Grade 4 & $.21^{\mathrm{a}}$ & 1.01 & $-.32^{\mathrm{ab}}$ & 1.07 & $-1.00^{b}$ & 1.06 \\
\hline
\end{tabular}

Means with the same superscript are not significantly different from each other.

Grade 4, the HR group differed significantly not only from the CC but also from the LR group in Work With ratings. Table 6 reports the means and standard deviations for each group.

In addition to the multivariate analysis of the peer ratings, the peer-nomination categorical data were examined. Based on the peer nominations, students were classified as either "rejected" or "not rejected," which combined the categories of average, popular, neglected, and controversial. Differences in classification rate were examined with chi square $\left(\chi^{2}\right)$. The $\chi^{2}$ was significant for each of the three points in time. Examination of the rates of rejection versus nonrejection as presented in Table 7 revealed that over the three time periods, the HR group maintained a high percentage of rejected students ( $68 \%$ to $70 \%$ ), the CC group maintained a low percentage (approximately $20 \%$ ) of rejected students, and the LR group dropped the percentage of rejected students from $39 \%$ to $30 \%$.

\section{TABLE 7}

\section{Rejection by Peers by Risk Status Groups}

$\begin{array}{cccc}\begin{array}{c}\text { Percentage of } \\ \text { Rejected Students } \\ \text { Risk Status Groups }\end{array} & \begin{array}{c}\text { Fall } \\ \text { Grade 3 }\end{array} & \begin{array}{c}\text { Spring } \\ \text { Grade 3 }\end{array} & \begin{array}{c}\text { Winter } \\ \text { Grade 4 }\end{array} \\ \text { CC } & 22 \% & 24 \% & 18 \% \\ \text { LR } & 39 \% & 43 \% & 30 \% \\ \text { HR } & 62 \% & 68 \% & 70 \%\end{array}$

To examine if the behaviors that identified the risk status of these students for EBD were affecting the students' self-esteem and self-perception, two $3 \times 3$ (Group $\times$ Time) repeated measures MANOVA utilizing the self-reported scores from the
SSCS were computed. The first MANOVA used the standard scores for Image, Academic, and Social self-concept across three points in time, and the second used the standard scores for the self-reported Importance of these same three domains.

In both analyses the model was not significant for either of the main effects or the interaction, and no post-hoc univariate analyses or comparisons were computed. Examination of the means by group in Table 8 demonstrates that subjects in the HR group perceived themselves as positively as did those in the CC group, and denoted the same level of importance to the three domains of self-concept as did the $\mathrm{CC}$ group.

\section{Discriminant Function Analyses}

In addition to the above analyses, a series of descriptive discriminant function analyses were conducted to identify the best subset of ordered variables to differentiate the three groups. Predictive, or classification, discriminant function analyses also were conducted to compute classification rates into the groups. Conversely related to a MANOVA, in discriminate analysis, the independent variables are the predictors and the dependent variables are the groups. To correct for capitalization on chance, these classification analyses were cross-validated using a jackknife procedure.

A series of three stepwise discriminate function analyses were conducted on the teacher measures (SSRS-T), and the peer sociometrics (and ratings). At each step of the analyses, the variable that maximized the explained variance between the groups (CC, LR and HR) ) was entered ( $\mathrm{p}<.15$ ).

In the stepwise discriminant function analysis conducted using the SSRS-T scales of Social Skills , Problem Behavior, and Academic Competence across the three points in time, the best predictors of risk status (in order of entry) were Social Skills, Fall Grade 3; Academic Competence, Spring 


\begin{tabular}{|c|c|c|c|c|c|c|c|}
\hline \multirow{2}{*}{$\begin{array}{l}\text { Risk Status Group } \\
\text { SSRS-T Problem. Behavior }\end{array}$} & \multicolumn{2}{|r|}{ Control } & \multicolumn{2}{|r|}{ Low Risk } & \multicolumn{3}{|c|}{ High Risk } \\
\hline & Mean & Standard Deviation & Mean & Standard Deviation & Mean & Star & ard Deviation \\
\hline \multicolumn{8}{|l|}{ Image } \\
\hline Fall Grade 3 & 101.1 & 16.2 & 98.4 & 20.7 & 102.9 & 8 & 15.4 \\
\hline Spring Grade 3 & 99.2 & 19.3 & 94.4 & 19.1 & 99.5 & & 21.8 \\
\hline Winter Grade 4 & 101.0 & 16.1 & 95.6 & 18.1 & 97.73 & & 19.4 \\
\hline \multicolumn{8}{|l|}{ Academic } \\
\hline Fall Grade $3^{\prime}$ & 104.8 & 13.8 & 100.8 & 16.4 & 103.0 & & 14.3 \\
\hline Spring Grade 3 & 102.5 & 15.9 & 96.5 & 18.4 & 99.4 & & 18.5 \\
\hline Winter Grade 4 & 106.0 & 13.9 & 97.2 & 18.9 & 100.5 & & 18.6 \\
\hline \multicolumn{8}{|l|}{ Social } \\
\hline Fall Grade 3 & 104.1 & 15.5 & 101.2 & 21.0 & 102.7 & & 19.5 \\
\hline Spring Grade 3 & 102.4 & 13.9 & 95.2 & 21.4 & 99.6 & & 15.4 \\
\hline Winter Grade 4 & 104.7 & 15.6 & 98.6 & 21.4 & 100.2 & & 18.8 \\
\hline Importance of Image & & & & & & & $=\quad$. \\
\hline Fall Grade 3 & 110.7 & 15.1 & 104.6 & 17.7 & 113.8 & & 14.0 \\
\hline Spring Grade 3 & 107.0 & 19.6 & 102.8 & 15.4 & 106.5 & & 19.0 \\
\hline Winter Grade 4 & 103.4 & 18.6 & 105.7 & 18.8 & 106.7 & & 20.5 \\
\hline \multicolumn{8}{|l|}{ Importance of Academic } \\
\hline Fall Grade 3 & 114.4 & 13.0 & 108.1 & 15.4 & 114.2 & & 13.7 \\
\hline Spring Grade 3 & 111.4 & 20.1 & 103.1 & 17.9 & 106.9 & - & 17.9 \\
\hline Winter Grade 4 & 114.7 & 13.3 & 108.4 & 20.0 & 111.5 & & 19.2 \\
\hline \multicolumn{8}{|l|}{ Importance of Social } \\
\hline Fall Grade 3 & 112.4 & 15.1 & 108.6 & 16.3 & 115.7 & & 15.7 \\
\hline Spring Grade 3 & 109.5 & 18.2 & 105.8 & 19.1 & 108.9 & & 17.4 \\
\hline Winter Grade 4 & 109.8 & 17.4 & 103.9 & 22.2 & 111.1 & & 18.1. \\
\hline
\end{tabular}

Grade 3; Problem Behaviors, Fall Grade 3; Academic Competence, Fall Grade 3; Problem Behavior, Winter Grade 4, and Problem Behavior, Spring Grade 3. This model was significant $E(12,252)=13.6 p>.001$, which accounted for $63 \%$ of the explained variance $(\lambda=.37)$. The cross-validated classification analysis correctly identified $65 \%$ of the HR group, $81 \%$ of the CC group, and $62 \%$ of the LR group, yielding a total error rate of $30 \%$.

Using the Work With z scores and the Play With z scores across all three points in time as entering variables of the peer sociometrics, the only two variables retained in the stepwise discriminant analysis was Work With $\mathrm{Z}$ scores at Winter Grade 4 and Spring Grade 3. This model was significant, $\mathrm{E}$ $(4.178)=7.13 \mathrm{p}<.0001$, which accounted for $26 \%$ of the explained variance $(\lambda=.74)$. Using the peer sociometric variables, the cross-validated discriminant function correctly classified $66 \%$ of the HR group, $65 \%$ of the CC group, and $23 \%$ of the LR group. The overall error rate was $49 \%$.
TABLE 8

Finally, a stepwise discriminant function was performed to maximize the predictive ability of the collected measures across information sources. The variables were selected based on the results of the previous MANOVAs: the SSRS-T scales at all points in time and the peer ratings of Work With $\mathrm{Z}$ scores across all points in time. Self-concept measures, which failed to differentiate the groups, were not entered.

The resulting model, utilizing four of the available variables, was highly significant and accounted for $71 \%$ of the variance $(\lambda=.29)$. The variables entered in the following order: Problem Behavior at Winter Grade 4; Social Skills at Fall Grade 3; Academic Competence, Winter Grade 4; and Peer Work With Z score, Winter Grade 4. Using the jackknife procedure the classification analysis correctly classified $70 \%$ of the CC group, $65 \%$ of the LR group, and $68 \%$ of the HR group, with an overall error rate of $33 \%$. Few of these errors resulted in a severe misclassification (i.e., HR in CC group or vice versa). 
Behavior Profiles :

The above analyses attest to the homogeneity of the HR group in terms of teacher and peer perceptions, particularly as compared to the $\mathrm{CC}$ group, and also when compared to the low-risk group. The difficulty in discerning degrees of prob- lem behavior and qualitatively different problem behavior of HR students from LR students is problematic for schools. To highlight the variability within the HR group we offer three case profiles in an attempt to (a) illustrate the trends in the

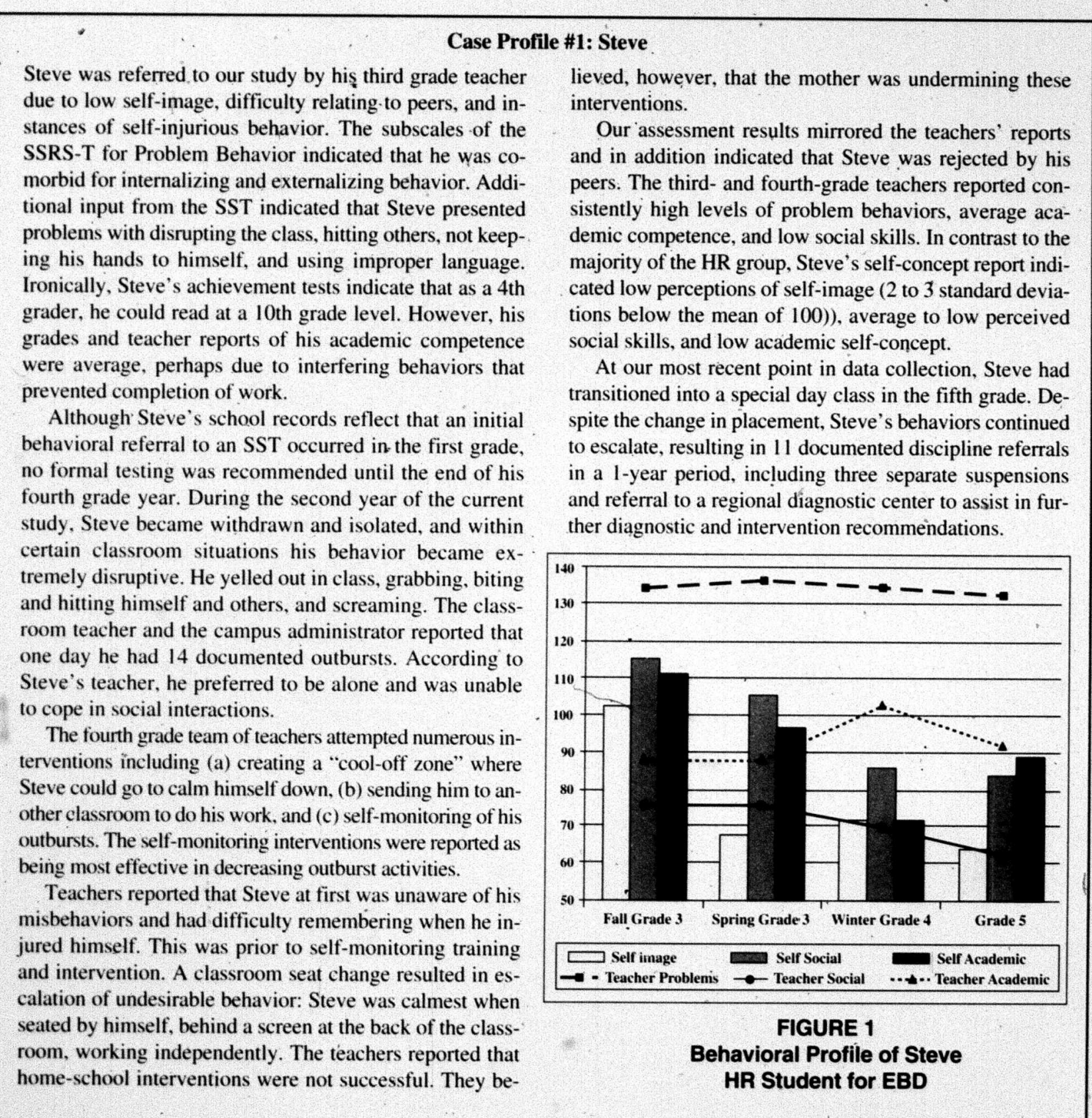


data at the individual level and, (b) accent the variability in placement, teacher perception of academic and behavioral problems, interventions and outcomes. Presented in each case profile are the individual's educational history along with teacher, peer, and self reported data collected over a two-year period. Unique to this section 'of our study is the valuable candid input from the student's teachers and their strategies for working with the challenging behaviors pre- sented by these children. Although not our primary goal, the case profiles illustrate the difficulty educators face regarding policy issues such as placement in the least restrictive environment. For example, the three students profiled here have been classified as EBD by research diagnostic criteria, yet the first case profile illustrates a special day class placement, the second profile highlights the transition of a student to a special day class after 3 years in a regular

\section{Case Profile \#2: José}

José was referred to a SST in the third grade for difficulty in all academic areas. Specifically, teachers noted his lack of reading and writing skills in both Spanish, his primary language, and English. At the time of our initial contact in the third grade, he had trouble spelling his first and last names and reversed letters and numbers. His teachers noted poor peer interactions and attributed this to a lack of self-esteem. José had more difficulty than most working with others in a cooperative group setting.

The SST recommended bilingual classroom services and decided that his externalizing behaviors would reduce with help. José was already working with a bilingual teacher in his classroom, however, and the SST recommendation did not change delivery of instructional services. By the end of third grade, José's acting out behaviors were escalating, and were accompanied by teasing from his peers, and symptoms of depression, such as a severe lack of interest in activities that previously were of interest.

These behaviors continued through the fourth grade. Academically, his teachers reported little to no.growth in reading and writing. Teacher observations indicate that he was easily frustrated, quit without trying, and had developed obsessive-compulsive behaviors.

By the fifth grade, José still was reading at a preprimer level, and formal assessment indicated that José qualified as having a specific learning disability that was not due to cultural or language issues. The IEP team believed that 4 to 6 hours a week with a resource specialist would be an appropriate placement. The RSP teacher's academic interventions included use of direct instruction, and a multisensory interactive approach with concrete materials. Behavioral interventions included isolating José's desk from his peers and utilizing logical consequences.

José is typical of our HR group in that his appraisal of self-concept (SSCS) was at or above the mean, despite low ratings in every dimension of classroom behaviors from teacher and peers alike. José described himfself as well liked, able to handle social situations successfully, a good student, and able to turn in work on time. His teachers countered with observations that peers avoided José, he had low social skills, low academic competence, and required frequent reminders to complete assignments. Although this discrepancy points to José's misperception of his behavior, he is not completely oblivious to environmental signals. Unique to José's profile, as seen in Figure 2, is a decline in perceived self-concept scores that coincided with a placement into special education.

Upon follow-up, José had transitioned into a middle school, where he receives all classes except physical education and his elective in a special day class. His teachers report that he has tantrums, uses obscene language, continues to exhibit sad affect, and remains neglected by peers.

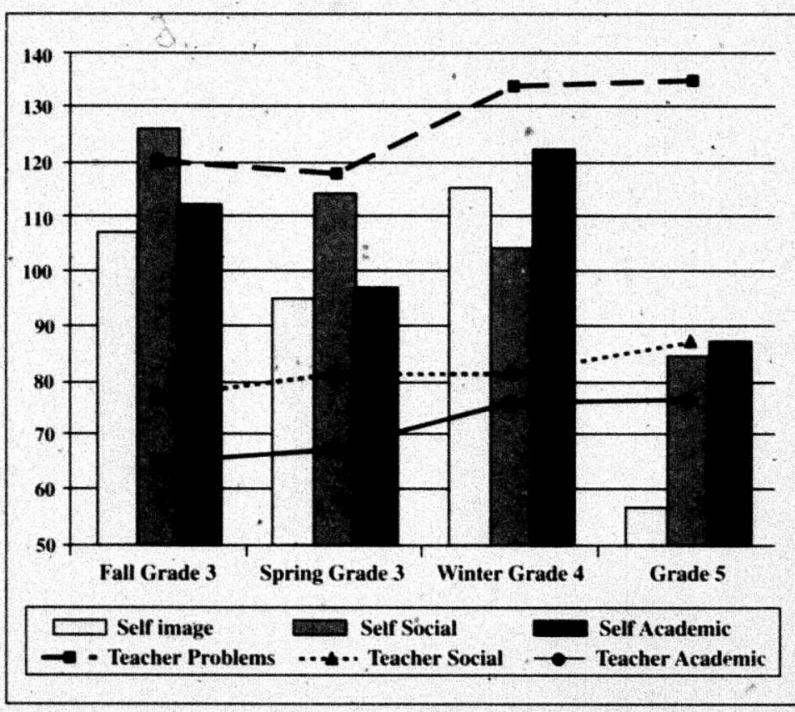

FIGỦRE 2

Behavioral Profile of José, HR Student for EBD 
classroom, and the third profile reflects the absence of any special educational services.

\section{DISCUSSION}

8

The results of this study demonstrate the utility of the CEI as a valuable tool for early identification, assessment, and classification of children with EBD. The combination of highly salient, low-frequency, internalizing and externalizing behaviors indexed by the CEI may be more indicative of a serious psychopathology. CEI scores successfully differentiated students at high risk for EBD, both from students with normal achievement and behavior and from students with varying degrees of at-risk status. The risk status determined by the CEI yielded large group differences across time ( 2 years), source of information (peers and teachers), and raters (changes in teachers and peers).

\section{Case Profile \#3: Louise}

Louise was referred to a student study team during her kindergarten year for both academic and behavioral concerns including low reading skills, poor social skills, behavior problems, failure to complete work, defiance, and having attention deficit disorder. The SST recommended a reading tutorial program and cut her homework by half. By third grade, Louise's standardized achievement test scores fell below the 7th percentile. She was becoming increasingly frustrated with schoolwork and evidenced off-task behaviors: being out-of-seat, talking out in class, teasing and criticizing others. Her teacher attributed Louise's low self-esteem to poor academic competence.

During the third grade, Louise's teacher reported an increase in her rebellious behaviors and defiance. In addition, the school staff noted that she was teased by her peers, complained often of severe headaches and other somatic disorders, and cried frequently. In the fourth grade, however, teacher interventions resulted in noticeable outcomes. Interventions were implemented for behavioral concerns, and a 504 modification plan accommodated het academic difficulties in the general classroom environment.

According to her teacher, the effectiveness of Louise's successful experience in the general classroom could be attributed to the home-school daily reports. A contract was established that isolated problems, established consequences, and emphasized Louise's responsibility for her actions. Positive behavior was reinforced with a teacher token economy. Teachers documented problem behaviors outside of the class in a playground journal. The identified problems were discussed with Louise and her mother and solutions were generated and attempted. Louise's desire to be part of the social group contributed to the success of the journal intervention.

The success of these interventions in the fourth grade were reflected in an upward trend of fifth grade self-concept scores across all domains (see Figure 3). Once the interventions were withdrawn when she was promoted to fifth grade, however, patterns of behavior more typical of her third- grade year reemerged. Louise's teacher reported high numbers of internalizing, externalizing, and hyperactive behaviors and rated her academic competence and social skills as being 1 to 2 standard deviations below the mean. Louise's peer group continues to reject her in both the classroom and playground environments.

One purpose of presenting case profiles is to illustrate individual differences among what purports to be a homogeneous group of students. Louise's history highlights the impact of one teacher's willingness and dedication to an intervention approach. Unfortunately, the impact of this teacher's effort did not last. The last report from her fifthgrade teacher indicated that Louise was stealing, physically aggressive with others, and causing damage to property.

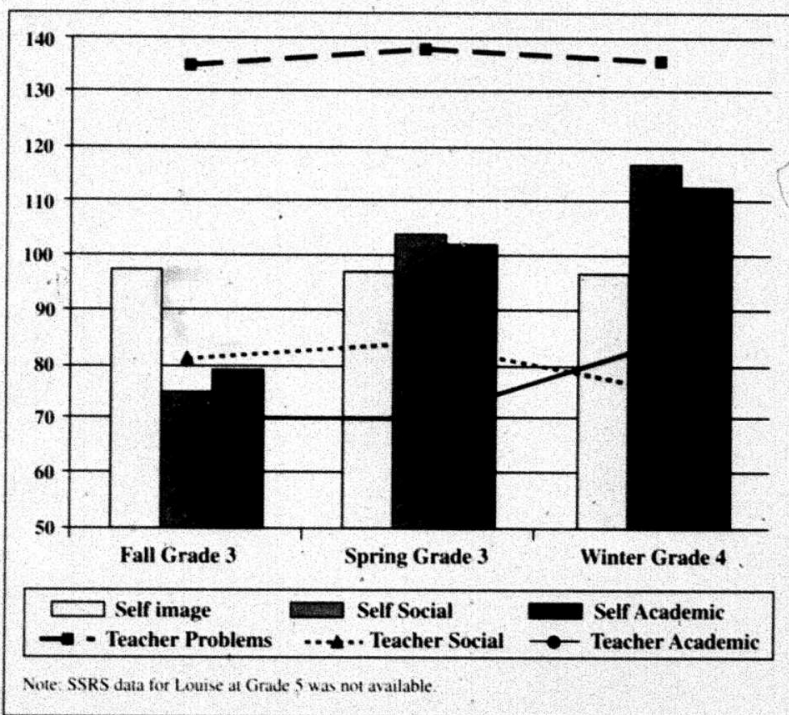

FIGURE 3

Behavioral Profile of Louise, HR Student for EBD 
The instrument is efficient to administer and score, taking no more than 5 minutes to complete, yet the classifications formed by CEI scores are supported by more complex, long-term data.

The data collected capture preliminary indications of each of the five educational criteria for the SED classification. For example, children classified as HR experienced significantly higher rates of peer rejection than either the LR or CC groups, demonstrating an inability to maintain satisfactory peer relationships, which is a criterion for SED. This indication of impaired social functioning is highly predictive of difficulties in school performance, psychopathology, and juvenile delinquency (Kupersmidt, Coie, \& Dodge, 1990). Another characteristic of the child with SED is inappropriate types of behavior under normal circumstances. Poor social skills, as measured by the SSRS-T, were evidenced by the HR group at all three times measured, even when compared to other at-risk children. Internalization of difficulties, such as depression and somatic complaints, was measured as one of three subscales of SSRS-T Problêm Behavior. Again, the HR group had significantly higher internalizing scores than both of the other groups.

In addition to differences in internalizing behaviors, the HR group had significantly higher scores on the externalizing and hyperactive subscales (see Figure 4). Although the higher mean scores are reason for concern in and of themselves, 23 students, over half of the HR group, were comorbid for internalizing, externalizing, and hyperactive behaviors (i.e., their score on each scale was above the mean). That is, they may exhibit hyperactivity in addition to aggressive, defiant behaviors, and simultaneously be depressed. This comorbid diagnosis has severe implications for future functioning. Research shows that children with concurrent ADHD and conduct problems display increased physical aggression, antisocial behavior, and underachievement, and receive higher rates of peer rejection than do children with either disorder alone (Hinshaw, Lahey, \& Hart, 1993). Overall, the complexities of comorbidity place children at a higher risk for future problems, and argues for their inclusion into the SED category (McConaughy, \& Skiba, 1993).

Figure 5 graphically depicts the group mean scores (averaged across the three time points) for the SSRS-T domains of academic competence, social skills, and problem behaviors. The HR group differs significantly from the LR and CC group on measures of social skills and problem behaviors, but does not differ from the LR group in academic competence until the fourth grade. This discrepancy captures the Catch-22 in the federal definition of SED. Although the behaviors noted by teachers (and peers) differ quantitatively and'qualitatively from LR students, the effect of these upon academics is harder to discern, particularly when held in comparison to other academically at-risk students. At what level of severity, after how

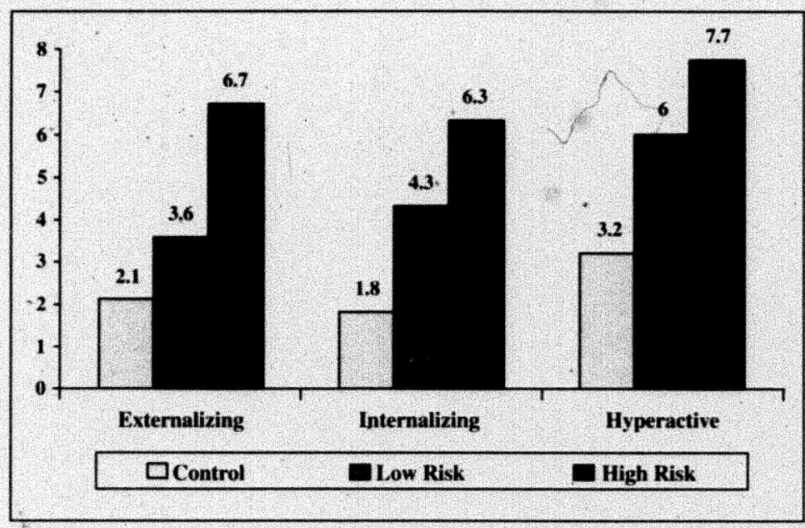

FIGURE 4

SSRS-T Problem Behavior Subscales By Group Averaged Over Three Points in Time

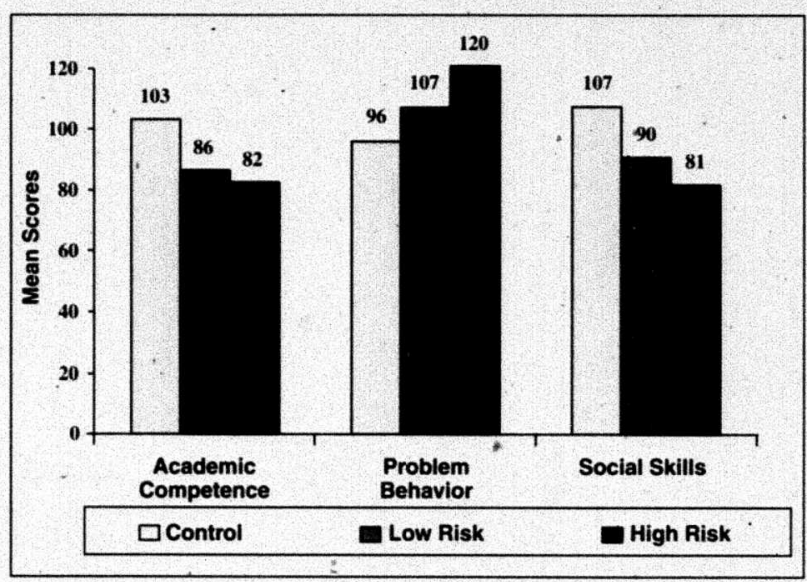

FIGURE 5

SSRS-T Scales by Group Averaged Over Three Points in Time

many interventions, do an individual's behavior disorders clearly impact academic school performance? Given that school performance is a broader domain than academic competence, how can we effectively define, at the earliest age possible, the variables that teachers and peers perceive?

Peer ratings, particularly in terms of whom children preferred to work with, also effectively predicted HR group membership. Significant peer rejection across time was noted for the HR group utilizing peer nominations (Table 7). These peer reports further separate the HR group from other at-risk students by the fourth grade, suggesting that in the absence of interventions, the peer relationships of the HR group continue to deteriorate. 
The self-report measure of self-concept, the SSCS, failed to differentiate the three risk status groups. Those in the HR group rated themselves high in terms of Social Skills, Academic Competence, and Self-Image. These ratings are highly discrepant from both teacher and peer ratings. Possible reasons for this discrepancy between reporters are that (a) HR students exaggerate their competence on self-reports; (b) HR students are giving the socially desirable answers (although it "should be noted that the SSCS has a "lie factor" scale built into the assessment, and only the scores from students who passed this portion of the assessment were included); or (c) HR students are unaware of the impact of their own behavior and how others perceive them.

Although our current data allow only for speculation as to the cause, two plausible explanations previously proposed in the literature include:

1. The inflated self-concept is a protective mechanism or a positive illusory bias (Hoza, Pelham, Milich, Pillow, \& McBride, 1993).

2. The self concept/observed behavior discrepancy is an early indication of adult psychopathology (Baumeister, R., Smart, L. \& Boden, J., 1996).

Regardless of source, the behavior/self-concept discrepancy may prove useful as a diagnostic insight for EBD identification and also pose a dilemma for teachers designing interventions. The assumption of what motivates behavior for these children may be diametrically opposed to other students and doom even the most consistently performed intervention to failure. In addition, for the students profiled here, a change in classroom placement preceded a drop in measurable selfconcept. It is not known if this drop in self esteem (as a reaction to classroom change) is atypical for the HR group, however the question warrants further research.

The behaviors noted here suggest more intensive interventions and classroom strategies, yet few of these HR students are placed in special education settings. Most of the HR students remain in general education classrooms, where teachers may have difficulties providing the services they require. The behavioral profiles suggest that teacher intervention can make a difference; however, among these three, the most successful interventions were based on identifying the controlling or maintaining behaviors and developing interventions based on individual needs. This strategy, known as functional assessment, will be described briefly as a strategy for use by general and special education teachers.

Functional assessment refers to a full range of strategies utilized in the identification of antecedent and consequent conditions that cause or maintain problem behaviors in or out of the classroom (Gresham, 1991). A functional assessment directly relates assessment to intervention by providing teachers and others with a systematic approach to uncover the specific antecedents and consequences of specific behaviors. A fundamental tenant of functional assessment is individualization, which purports that all children have different behavioral repertoires, learning histories, and intervention needs, that will have implications for development of interventions (Wolery, Bailey, \& Sugai, 1988). An individual, comprehensive assessment of problem behavior marks the first step to effective intervention. Four requirements are necessary to conduct a functional assessment:

1. Problem behaviors must be operationally defined.

2. Antecedent events that predict occurrence and nonoccurrence of problem behaviors must be identified.

3. Hypotheses are developed regarding consequent events that are maintaining the target behavior.

4. Direct observational data must be collected to ensure that hypotheses are based on systematic behavioral observation and data, not on assumptions, opinions, or casual observation. The systematic observation is what key is for successful intervention with children at risk for EBD.

Although more time-consuming initially than more "cookbook" approaches, the ease with which high-risk students may be identified with the CEI, and the higher probability of intervention success, offsets the investment. It represents an alternative to spending long hours with highly trained personnel in establishing a diagnosis, and relatively few selecting a treatment.

More efficient and accurate assessment methods are markedly necessary with reference to SED/EBD identification, classification, and intervention. Although early identification is more feasible with utilitarian instruments such as the CEI, differentiation does not necessarily precipitate classification or placement. As such, general education classroom teachers will continue to identify and serve these children within a general education classroom. Further research regarding the distinguishing characteristics of children at high risk for EBD, particularly in response to early interventions, is crucial.

\section{REFERENCES}

Achenbach, T. M (1985). Assessment and taxonomy of child and adolescent psychopathology. Newbury park, CA: Sage

Baumeister, R., Smart, L., \& Boden, J. (1996). Relation of threatened egotism to violence and aggression: The dark side of self esteem. Psychological Review, 103, 5-33.

Campbell, M., Gonzalez, N., \& Silva, R. R. (1992). The pharmacological treatment of conduct disorders and rage outbursts. Psychiatric Clinics of North America, 15(1), 69-84. 
Coie, J. D., Dodge, K. A., \& Coppotelli, H. (1982). Dimensions and types of social status: A cross-age perspective. Developmental Psychology, 18, 557-570.

Dodge, Y. (1985). Analysis of experiments with missing data. New York: Wiley \& Sons.

Duncan, B. B., Forness, S. R., \& Hartsough, C. (1995). Students identified as seriously emotionally disturbed in day treatment: Cognitive, psychiatric and special education characteristics. Behavioral Disorders, 20, 238-252.

Edelbrock, C. S. (1983). Problems and issues in using rating scales to assess child personality and psychopathology. School Psychology Review, 12, 293-299.

Gresham, F. M. (1985). Behavior disorder assessment: Conceptual, definitional, and practical considerations. School Psychology Review, 14, 495-509.

Gresham. F. M., \& Elliott, S. N. (1990). Social skills rating system (SSRS). Circle Pines, MN: American Guidance Service.

Gresham, F. M., Elliot, S. N., \& Evans-Fernandez, S. E. (1993). Student self-concept scale - Student. Circle Pines, MN: American Guidance Service.

Gresham, F. M. \& Lambros, K. M. (1997). Behavioral and functional assessment. In T. S. Watson \& F. M. Gresham (Eds.), Child behavior therapy: Ecological considerations in assessment, treatment, and evaluation. (pp 3-22). New York: Plenum Press.

Gresham, F. M., MacMillan, D. L., \& Bocian, K. M. (1996) Behavioral earthquakes: Low frequency, salient behavioral events that differentiate students at-risk for behavioral disorders. Behavioral Disorders, 21, 277-292.

Hinshaw, S. P., Lahey, B. B., \& Hart, E. L. (1993). Issues of taxonomy and comorbidity in the development of conduct disorder. Development \& Psychopathology, 5, 31-49.

Hoza, B., Pelham, W., Milich, R., Pillow, D., \& McBride, K. (1993). The self-perceptions and attributions of attention deficit hyperactivity disordered and nonreferred boys. Journal of Abnormal Child Psychology, 21, 271-286.

Kaufman, J. M., \& Wong, K. I. (1991) Effective teachers of students with behavioral disorders: Are generic teaching skills enough? Behavioral Disorders, 16, 225-237.

Kazdin, A. E., (1987). Conduct disorders in childhood and adolescence. Beverly Hills, CA: Sage.

Kupersmidt, J., Coie, J., \& Dodge, K. (1990). The role of poor peer relationships in the development of disorder. In S. Asher \& J. Coie (Eds.), Peer rejection in childhood (pp 274-308). New York: Cambridge University Press.

Loney, J. (1987). Hyperactivity and aggression in the diagnosis of attention deficit disorder. In B. B. Lahey \& A. E. Kazdin, Eds., Advances in clinical child psychology, 10. New York: Plenum.

MacMillan, D. L., Gresham, F. M., \& Forness, S. R. (1996). Full inclusion: An empirical perspective. Behavioral Disorders, 21, 145-159.
MacMillan, D. L., Jones, R. L., \& Aloia, G. F. (1974). The mentally retarded label: A theoretical analysis and review of research. American Journal of Mental Deficiency, 79(3), 241-261.

MacMillan, D. L., Gresham, F. M., Bocian, K. M. (in press) Curing mental retardation and causing learning disabilities: Consequences of using various WISC-III IQs to estimate aptitude. Journal of Psychoeducational Assessment.

McConaughy, S. H., \& Skiba, R. J. (1993). Comorbidity of externalizing and internalizing problems. School Psychology Review, 22, 421-436.

Safran, J., \& Safran, S. (1987). Teachers' judgments of problem behaviors. Exceptional Children, 54, 240-244.

Slenkovich, J. E. (1992). Can the language "social maladjustment" in the SED definition be ignored? School Psychology Review, 21, 21-22.

Tabachnik \& Fidell, 1989.

-Smith, C. R., Wood, F. H., \& Grimes, J. (1988). Issues in the education of behaviorally disordered students. In M. C. Wang, M. C. Reynolds, and H. J Wahlberg (Eds.), Handbook of special education: Research and practice (Vol. 2). Oxford, England: Pergamon Press.

U.S. Department of Education, 1991

Walker, H. M., \& Fabre, T. R. (1987) Assessment of behavior disorders in the school setting: Issues, problems, and strategies revisited. In N. Haring (Ed.), Measuring and managing behavior disorders (pp. 198-243). Seattle: University of Washington Press.

Walker, H. M., Colvin, G., \& Ramsey, E. (1995). Antisocial behavior in school: Strategies and best practices. Albany: Brooks/Cole.

Walker, H. M., \& Severson, H. (1990). Systematic Screening for Behavior Disorders: Technical Manual. Longmont, CO: Sopris West, Inc.

Webster-Stratton, C. (1993). Strategies for helping early schoolaged children with oppositional defiant and conduct disorders: The importance of home-school partnerships. School Psychology Review, 22, 437-457.

Wolery, M., Bailey, D. \& Sugai, G. (1988). Effective teaching principles and procedures of applied behavior analysis with exceptional students. Boston: Allyn \& Bacon.

This work was supported in part by grants \# HC023C20002, $\mathrm{H} 023 \mathrm{C} 30103$, and $\mathrm{H} 023 \mathrm{C} 70134$ from the Office of Special Education Research, U.S. Office of Education. We would like to thank and acknowledge Stacy Harshman and Stephanie Sultany for their work in data collection with the students and teachers. Opinions expressed herein are those of the authors alone and should not be interpreted as having the endorsement of the agency. 